\title{
IDENTIDADES IMAGINADAS: UMA AUTOBIOGRAFIA ROMÂNTICA NAS CARTAS DE EMILY DICKINSON
}

\author{
Luis André Nepomuceno \\ nepomuc@terra.com.br
}

A correspondência epistolar com amigos e familiares parece ter sido, para Emily Dickinson, quase um motivo de sobrevivência. Para Thomas Higginson, crítico literário admirado do séc. XIX, a quem ela enviara poemas e cartas, e com quem manteve correspondência por quase 25 anos, Dickinson escreveu certa vez que ele, sem ter consciência disso, havia lhe salvado a vida (C330, p. 460)․․ Já era o ano de 1869, e a poeta de Amherst vinha mantendo uma profícua interlocução com Higginson desde 1862, mas curiosamente o crítico não lhe tinha sido generoso na leitura dos poemas que recebera por carta. Chegara mesmo a desestimular a escritora em possíveis projetos de publicação. Difícil, portanto, entender por que Dickinson, poeta reclusa e obscura do interior americano, lhe atribuía essa responsabilidade de "salvar a vida", justo ele que, embora tenha se sentido fascinado pela personalidade da jovem, admitia que os poemas não estavam inteiramente prontos para edição. Decepcionada muito embora, ainda que não demonstrasse isso nas cartas, Emily Dickinson insinuava outra realidade, esta invisível ao crítico: a de que a epistolografia era, para ela, exercício indispensável e decisivo à literatura

1 As cartas de Emily Dickinson serão referidas pela sua numeração, precedida de C (Carta), a partir do volume DICKINSON (1960), editado por Thomas Johnson. 
e, ao mesmo tempo, uma das mais preciosas estratégias de comunicação com o mundo. Por outro lado, e ao mesmo Thomas Higginson, ela dizia que publicar os poemas era algo inteiramente alheio a seus propósitos de vida.

Martha Nell Smith, no entanto, aponta que embora Emily Dickinson não tenha publicado seus versos em livro, salvo raríssimas exceções, e por decisão de terceiros, ela o fez de forma diversa, incluindo-os nas muitas cartas enviadas a amigos e familiares (SMITH, "A Hazard of a Letter's Fortunes: Epistolarity and the Technology of Audience in Emily Dickinson's Correspondences", in EBERWEIN \& MACKENZIE, 2009, p. 241). Dentre os quase 1800 poemas de seu corpus literário, uma imensa parte foi extraída de dentro do epistolário. A prática de escrever cartas assumiu para a poeta, portanto, uma natureza dupla: de um lado, a construção mais íntima de relações pessoais e afetivas; de outro, o espaço da interlocução poética e reflexiva, motivo de aprofundamento na própria natureza da poesia, mesmo que apenas Thomas Higginson e Susan Gilbert Dickinson (cunhada da poeta) lhe tenham retribuído o envio de poemas, com uma possibilidade efetiva de interlocução (idem, p. 242). Mais importante que isso, no entanto, eram os haveres da palavra "publicada", embora não editada, impressa, porém distribuída a cada um de seus interlocutores, pessoalmente. "A carta sempre me parece como a imortalidade, pois que é a própria mente em si sem a presença física”, ela

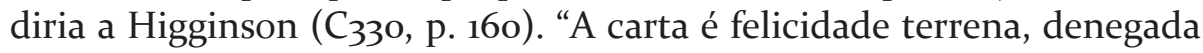
aos deuses”, ela escreveria aos amigos Mary e Eben Jenks, numa carta em formato de poesia, versos que seriam depois também destinados a Charles Clark (FRANKLIN, 1998, III, p. 1465-66). Num dos vários cadernos manuscritos encontrados na gaveta depois de sua morte, Emily Dickinson deixa um curioso poema ("The way I read a letter's this"), em que expõe ao leitor o êxtase único de receber uma carta: a porta do quarto fechada, a certeza de estar só, a emoção na intimidade com o outro, o ritual da leitura, o desejo de um céu, mas não o céu dos sermões calvinistas ( $\mathrm{P}_{700 \text {, }}$ II, p. 669)². Estava certo que, para a reclusa poeta de Amherst, epístola e poesia eram gêneros equivalentes. Em ambos, ela manteve o exercício de construir uma imagem de si mesma, como forma de criar um vínculo com os outros e estabelecer estratégias de comunicação, a partir de suas leituras e reflexões pessoais.

Dickinson escreveu cartas desde 1842 (menina de 11 anos de idade), até o fim da vida, em 1886: seu epistolário compõe um rico acervo de 1046

2 Os poemas de Emily Dickinson serão referidos pela sua numeração, precedida de P (Poema), a partir do volume DICKINSON (1998), editado por R. W. Franklin. 
cartas a quase 100 interlocutores diferentes (na edição de Johnson, 1960), verdadeiro patrimônio literário, face à consciência crítica e poética da autora. Se poesia e epístola eram gêneros equivalentes, a ponto de a carta lhe salvar a vida do naufrágio existencial, é justo reconhecer nesse acervo um status de literatura, e buscar nele uma identidade que se construiu ao longo de toda uma vida, a exemplo do que se depreende também dos poemas da autora. Ler o imenso corpus epistolográfico da poeta é um exercício de reconstrução dessa mesma identidade, na medida em que ela se desdobra em variações, em temas, em composições poéticas, em multiplicidades identitárias, enfim - no entanto, todas elas a compor a representação de um único sujeito poético, objeto desta pesquisa. Pelo menos a julgar pela epistolografia medieval e humanista, que teria arrastado modelos até o séc. XVIII, em que a carta funcionava como gênero de interlocução filosófica, ou por vezes, como exposição de ideais políticos; ou ainda a julgar pela epistolografia contemporânea, veículo de conversação sobre intimidades ou mero diálogo sobre ideais estéticos, políticos ou sociais entre grandes escritores, o caso de Emily Dickinson é bastante singular. E sobre isso há pelo menos dois pontos a considerar: 1) não há uma intencionalidade argumentativa que identifique o conjunto das cartas, ou seja, não é possível rastrear na totalidade do corpus uma consciência "pública", em que pese o artifício da arte como veículo que será levado posteriormente a um destinatário universal, ou antes, a um público leitor, e nesse sentido, Dickinson deixa-se flagrar pelo sabor da intimidade e da casualidade; 2 ) a poeta, embora tenha escrito a pessoas inteligentes e sensíveis de sua época, não dialogou com a vanguarda norte-americana do séc. XIX, o que implica certa incompreensão da parte de seus interlocutores. Aliás, iria mais longe: em diversos momentos, ela falou sozinha.

Em síntese, tudo isso quer dizer que o exame desse volumoso corpus literário, parte dele encontrado entre os espólios da escritora, deve levar em conta que Emily Dickinson não o projetou como tal. A organização de um todo epistolográfico lhe teria sido alheia aos propósitos ${ }^{3}$. Da casa de seu pai em Amherst, Massachusetts, ela simplesmente escreveu cartas. Contudo, esse material, a princípio amorfo, parece adquirir contornos

3 Eberwein e Mackenzie (2009, p. 1) apontam, por exemplo, que o costume da Nova Inglaterra do séc. XIX era queimar os pertences das pessoas falecidas, incluindo cartas, e que o acervo publicado de Emily Dickinson deve compor não mais que um décimo de sua produção total. Em outros termos, é possível que não tenha havido nela a intenção de que a carta pudesse significar um registro histórico de sua própria obra, a despeito das intenções visivelmente literárias ali contidas. 
argumentativos, compondo inclusive eixos temáticos, à medida que se traz à luz a relação de proximidade retórica nas diversas composições. Ainda que o delineamento fragmentário e caótico das cartas, a par do estilo enigmático, por vezes quase impenetrável da autora, revele casualidade e diversidade temática (são cartas de notícias familiares, cartas amorosas, eróticas, filosóficas, indagadoras, consolatórias, obscuras, poéticas, ou até mesmo bilhetes acompanhados de flores ou presentes diversos), tarefa das mais significativas é tentar compor um quadro geral de sentidos desse sujeito identitário e poético que emerge dos diversos planos retóricos da epistolografia.

Sabendo da impossibilidade, ou pelo menos do desinteresse de publicar sua poesia em livros, Emily Dickinson preferiu partilhar os versos com amigos, naquele espírito de acolhimento e intimidade descrito no poema 70o. Daí surgirem pelo menos três subgêneros no seu acervo: a carta propriamente dita, o poema, e a carta-poema (HART \& SMITH, p. xxv) - modelos de certa forma vagos, com fronteiras imprecisas, no entanto úteis para o entendimento da "função" pessoal da carta nos diversos momentos da vida da poeta. Dickinson, por exemplo, presenteou amigos com flores, frutas, comidas, sempre acompanhados de uma carta, ou de um poema, eventualmente como retribuição a alguma visita, ou em decorrência de qualquer episódio social, o que faz com que muitas dessas cartas estejam vinculadas a contextos pessoais da vida dos interlocutores, em que apenas o receptor poderia, por exemplo, decifrar enigmas por certo contidos naquele contexto (TINGLEY, Stephanie, “'Blossom[s] of the Brain': Women's Culture and the Poetics of Emily Dickinson's Correspondence", in EBERWEIN \& MACKENZIE, 2009, p. 62). Disso decorrem particulares inusitadas, num jogo entre arte e vida quotidiana, retórica e banalidades. Antes de tudo, motivo central na vida da poeta, conforme seu próprio depoimento.

Dickinson, a julgar por esse panorama histórico, estava não mais que cumprindo um papel que lhe cabia numa ordem social da Nova Inglaterra vitoriana. Amherst era uma cidadezinha provinciana, conservadora, de forte tradição calvinista, e Edward Dickinson, pai de Emily, representava em meados do século a austera figura do homem público, misógino, moralista e ortodoxo, a impor um modelo de severidade à filha poeta, o que, por certo, tirou dela a coragem de ser publicamente letrada e participar das rodas e conversações mais cultas (HABEGGER, 2002, p. 47-50; KIRK, 2004, p. 11-16). A poesia ficou na gaveta, mas as cartas fizeram as vezes de comunicação com o mundo. E cartas plenas de boa poesia. Mas para isso, a escritora teve de subverter muitas das imposições e imaginários relativos à epistolografia feminina de seu tempo. Às mulheres de família 
da classe média alta da Nova Inglaterra cabia o papel de fazer sala aos amigos, bem como sustentar a civilidade em situações de boa vizinhança e, por fim, escrever cartas e notas, seja em situações de nascimento, congratulações, casamento ou consolação. Emily, portanto, consolou as viúvas, os doentes, animou os desconsolados, congratulou os meritórios ${ }^{4}$. Mas isso é quase nada em suas cartas, senão apenas um pretexto para a figuração mais sólida de uma epistolografia conscientemente literária, sobretudo se consideramos aquela figura excêntrica que ela cultivou a seus pares, e sobre quem corriam à boca pequena as notícias de uma mulher enclausurada, solteirona neurótica, misantropa, doentia - esse mito que ela própria ajudou a manter. A poeta, aos poucos, trocou a civilidade pela correspondência, a sala de visitas pelo quarto fechado, mas ainda assim comunicando-se com o mundo, exercendo, de certa forma, o papel da moça de família, porém ao mesmo tempo, e contraditoriamente, fugindo a ele, resguardando-se na intimidade, naquele espaço em que é possível conversar com o outro (em vãos monólogos, muito embora) e manter vivo o ardor de sua poesia. Por meio da carta.

Frente às lendas que se criavam em torno da figura outsider, a publicação das cartas de Emily Dickinson, depois de sua morte, foram aguardadas com excitação. Em 1894, Mabel Loomis Todd, amante de Austin Dickinson (irmão de Emily), que já vinha publicando pelo menos dois volumes de poesia da escritora, lançou no mercado uma coletânea das cartas de Emily, edição que, para espanto de todos, arrastou decepção aos que esperavam encontrar ali um motivo bombástico de revelações pessoais, como os amores e os mistérios que envolviam a vida da poeta (EBERWEIN \& MACKENZIE, 2009, p. 5). O epistolário de Emily Dickinson, ao contrário, representava coisa diversa: era o espaço de uma investigação profundamente retórica e reflexiva sobre si mesma, sobre o mundo, sobre o amor, sobre a morte, sobre Deus, sobre a condição humana. E bem no encalço de sua poesia: canhestro, obscuro, enigmático, lírico. Bilhetinhos pessoais, cartas a colegas de ginásio e outras banalidades se misturavam a verdadeiras obras de arte, endereçadas a algumas figuras mais ou menos ilustres de seu tempo. A estereotipia de papéis sociais da mulher vitoriana, somada às práticas e saberes comportamentais daquele tempo, dava espaço a um motivo de

4 "She wrote thank-you notes and letters of congratulation on births, marriages, and graduations; she cheered the sick and offered solace to the bereaved. Witty notes often accompanied gifts to neighbors and friends. Fruit or flower from her yard, desserts or wine from her kitchen, poems from her pencil - all were sent as tokens of her affection" (TINGLEY, in EBERWEIN \& MACKENZIE, 2009, p. 59). 
arte maior.

E foi justamente no plano da epistolografia que Emily Dickinson exerceu a outra parte do ofício de poeta, e pôde elaborar uma espécie de autobiografia, dispersa, fragmentada, heterogênea, como folhas em debandada, obscurecida pela linguagem poética, e toda ela sustentada na leitura recolhida no silêncio do quarto: a prática reclusa do poeta romântico. É certo que há uma invisibilidade na atitude autobiográfica em si, e as cartas só adquirem contornos de significação à medida que compõem um acervo e, sobretudo, quando, juntas, elaboram intenções visíveis de um sujeito identitário, e quando dialogam com os demais escritores de seu tempo. A aproximação das cartas da poeta de Amherst com os ensaios de Ralph Waldo Emerson e David Thoreau, por exemplo, parece inevitável. Por diversas vezes ela os menciona na correspondência com amigos, reconhece o poder de sua influência, discute seus pensamentos mais fortes e polêmicos, admitindo-lhes a força do influxo criativo. Thomas Johnson (1965, p. 250), um de seus primeiros biógrafos, deixa clara a proximidade: "As duas forças intelectuais e espirituais que influenciaram o seu pensamento foram as tradições puritanas da sua família e do ambiente à sua volta, e as doutrinas românticas e transcendentais que começavam a generalizar-se na Nova Inglaterra da sua juventude". Será válido dizer, a esse respeito, que a identidade romântica imaginada por Emily Dickinson na interlocução com amigos teria sido elaborada em conformidade com o espírito transcendentalista, tão em voga nas letras americanas de meados do século, especialmente a partir dos ensaios de Emerson e Thoreau. Sobre isso, uma anedota biográfica parece tornar a história mais intrigante: Dickinson perdeu propositadamente uma oportunidade de conversação, e quem sabe de uma correspondência duradoura com o próprio Emerson, quando o já famoso ensaísta visitou Austin Dickinson, o irmão de Emily, que morava na casa da frente. Emily recusou-se a ir ter com ele, conquanto o tivesse em grande conta, na condição de modelo intelectual. Extravagância? Não, por certo em decorrência daquela timidez de participar das rodas literárias. Afinal, Emerson era uma celebridade.

O séc. XIX vinha assistindo ao surgimento de bons ensaístas na literatura americana: Washington Irving, James Lowell, e os próprios Emerson e Thoreau - todos eles mais ou menos identificados com o espírito romântico, ou com o ideal transcendentalista que vinha tomando fama nos meios intelectuais. Emily Dickinson, reclusa, intimidada demais para expor pensamentos em público, não aderiu ao gênero, mas apreciou-lhe o formato, e por certo o teve como referência decisiva para 
pensar ideias próprias. A autobiografia, a epistolografia, o ensaio, enfim, todos esses gêneros cultivados no século do Romantismo pareciam manter entre si uma proximidade genérica, a refletir o ideal de ruptura com a rigidez de outras formas fixas e a consolidar a égide do indivíduo no centro das polaridades ideológicas e das forças sociais.

Diante desse novo cenário, é preciso primeiro apagar a ideia de uma Emily Dickinson tão inteiramente enclausurada que teria escrito obra literária sem referências prévias ou diálogos com seus pares, conforme quiseram crer os primeiros biógrafos. Cynthia Wolff ("Emily Dickinson", in PARINI, 1993, p. 121-147) prefere acreditar numa escritora que, a despeito da conduta provinciana, não poderia inspirar a visão equivocada da poeta genial e espontânea, sem conhecimento da tradição. Wendy Martin ("Emily Dickinson", in ELLIOTT, 1988, p. 610) também aponta para a poeta disciplinada e consciente das transgressões do cânone. Dickinson soube manipular as formas e os gêneros disponíveis em torno de uma obra conscientemente elaborada, mesmo na fragmentação das cartas. Richard Sewall (1997, p. 532), um de seus mais expressivos biógrafos, ensina que é preciso distinguir duas identidades em Emily Dickinson: a real, e a imaginária; a da vida concreta, e a do mito criado por ela mesma.

Interessa-nos o mito, a personagem, a identidade imaginada, aquela que se elabora na autobiografia contida nas cartas e na poesia. "Quando exponho a mim mesma, como representativa do verso", ela escrevia a Higginson em 1862 (C268, p. 412), "isso não quer dizer que seja eu - mas uma pessoa imaginária”. Supposed person, seria a expressão utilizada por ela. A julgar por uma estratégia como essa, Cindie Mackenzie ("This is my letter to the World: Emily Dickinson's Epistolary Poetics", in EBERWEIN \& MACKENZIE, 2009, p. 16) define que Dickinson não nos deixa vestígios de uma autobiografia legítima, mas ao contrário, prefere os passos de uma autobiografia idealizada, elaborada, construída, em conformidade com o sujeito poético que ela andava bosquejando nos versos. Nas cartas, não se trata, portanto, de Emily Dickinson propriamente, mas de uma identidade outra, literária acima de tudo, evocada como artifício de ficção e literariedade. Em outros termos, a persona. O próprio Higginson, mesmo depois de anos de correspondência (que durou por toda a vida dela), ainda se perguntava se ela realmente existia ou se era ficção: "I think if I could once see you \& know that you are real, I might fare better" (C330a, p. 461). Os dois se encontrariam apenas em 1870. Antes disso, a poeta lhe parecia um mito literário.

Emerson ensinava, no texto de abertura dos seus Ensaios: primeira 
série (1841), que a totalidade da história está no homem, no indivíduo, e que a identificação entre todos os homens faz com que o tempo inexista: "todos os fatos públicos devem ser individualizados, e todos os fatos particulares hão de ser generalizados. Assim é que, de uma só vez, a História torna-se fluida e verdadeira, e a Biografia profunda e sublime" (EMERSON, 1994, p. 22). Walt Whitman, por quem Dickinson não teve lá grandes simpatias (apesar de não ter lido seu livro), respondia em uníssono no seu "Song of Myself", em que o eu centralizava as experiências cósmicas de toda a humanidade. A jovem Emily deve ter se sentido tocada a fundo pela potencialidade universal que haveria de caber nas singularidades de um indivíduo, porque tão logo se adequou ao ofício de poeta, buscou de imediato a filosofia da reclusão romântica, acreditando na "biografia profunda e sublime" que sua identidade poderia lhe render. E deve ter entendido com limpa consciência que a identidade lírica era construída nas bases da própria universalidade. Eram sem dúvida as primeiras lições de Emerson que, no ensaio "O poeta", incluído nos Ensaios: segunda série (1844), alardeava a eternidade da poesia, somada a sua expressão universal, reconhecendo, contudo, que pelo menos até então, a América ainda não tinha fecundado o seu grande e eterno poeta: "Não tivemos ainda um gênio na América, de olhar inexorável, que soubesse ver o valor de nossos materiais incomparáveis [...]" (EMERSON, 1966, p. 142). Whitman pode ter entendido que esta era uma missão que lhe cabia, porque assim que concluiu a primeira edição do seu Leaves of Grass, encaminhou o volume ao famoso ensaísta, e dele recebeu as melhores loas. Dickinson, mulher, caladinha, provinciana, amargando em casa as consequências da ortodoxia calvinista, por certo não teria aceitado a provocação. No entanto, as lições de Emerson chegaram-lhe à consciência aberta, modificando substancialmente sua poesia, e por extensão, os valores e ideais contidos nas epístolas.

Ainda mocinha, escrevendo cartas às amigas do ginásio, Emily já parecia disposta a evoluir no seu ideal de identidade postiça e imaginada. Na edição moderna de Thomas Johnson, já nas primeiras 40 cartas (escritas entre 1842-1846), é possível entrever um quadro subjetivo que ela própria vinha esboçando de si, promovendo junto às amigas a figura da rebelde anticlerical e antirreligiosa e da jovem transgressora de valores morais, a exibir condutas nada aceitáveis para a provinciazinha puritana. Pura fantasia. Dickinson jamais fora moralmente rebelde; ao contrário, submeteu-se às ordens do pai, malgrado a sua indisposição religiosa e seu abandono da igreja, depois da idade madura. E nem por isso a família a enxergou como grande insurgente ou revoltosa. O próprio 
pai, severo, conservador, teria tido sua "experiência de conversão" quase aos 50 anos. Mas Emily entendeu que seu papel, pelo menos em certas instâncias imaginárias da epistolografia, era o de promover a legitimação da desobediência, a exemplo da Desobediência civil de Thoreau. Numa carta de 1850 à jovem amiga Jane Humphrey, define-se, por exemplo, como a rebelde com bandeira hasteada contra as motivações calvinistas de sua família: "Christ is calling everyone here, all my companions have answered, even my darling Vinnie believes she loves, and trusts him, and I am standing alone in rebellion [...]" (C 35 , p. 94). Antes disso, teria provocado a amiga de forma ainda mais cínica, dizendo que a distância entre elas, afora a saudade e o amor que se rompe, poderia ser favorável, para que Emily não lhe servisse de tentação e má companhia: "you are out of the way of temptation - and out of the way of the tempter - I didn't mean to make you wicked - but I was - and am - and shall be - and I was with you so much that I couldn't help contaminate" ( $\left.C_{30}, p .83\right)$. Em outros termos, a jovem Emily disseminou de si, junto às amigas, a imagem da insurgente que é má companhia - representação da rebeldia de fundo romântico, quase anseio de personagem.

$\mathrm{O}$ anticlericalismo e o anticalvinismo iriam evoluir bastante na obra de Emily Dickinson, o que torna um mistério o seu contraditório anseio pela amizade de homens mais velhos e ligados às correntes eclesiásticas mais ortodoxas de seu tempo. Benjamin Newton, exceção entre eles, uma das primeiras amizades intelectuais de Emily, simpatizante das tendências unitaristas da época (precursores, inclusive, do próprio transcendentalismo), deve lhe ter ensinado os primórdios de uma rebeldia anticalvinista, bem mais em conformidade com o espiritualismo romântico da jovem que se formava nas letras. Em 1857, Newton a presenteava com uma edição dos Poemas de Emerson (HABEGGER, 2002, p. 222). Mas era o próprio Emerson quem consolidava nos Estados Unidos, e na própria consciência da jovem Dickinson, sobretudo a partir de seu ensaio "Autoconfiança” (contido na primeira série), a sugestão inovadora de uma prática religiosa quase sem intermediários, sem templos, sem deuses, toda ela centrada na universalidade contida no pensamento mais íntimo e verdadeiro do indivíduo. Emerson, que renunciara à Igreja e se tornara um pensador místico, platônico e não-dogmático, expunha então uma doutrina da "sabedoria em casa" (EMERSON, 1994, p. 59), em que resistia ao velho calvinismo doutrinário para lançar mão de uma religião inspirada na própria solidão espiritual e no silêncio.

A repulsa antidogmática de Emily Dickinson criou raízes que ultrapassaram as fronteiras da religião. Nas cartas da primeira fase, ela mistura a antipatia clerical, na forma da austeridade sufocante do 
calvinismo, com disposições pessoais para uma espécie de "religião" amorosa e sentimental centrada também no indivíduo, a exemplo de Emerson. Barton Levi St. Armond (2009, p. 85) a define como uma sentimental love religion. São no mínimo emblemáticas algumas das cartas que ela envia à cunhada Susan Gilbert, por quem Dickinson parece ter devotado um amor extraordinário, seja de qual natureza for ${ }^{5}$. Na carta 96, de 1852, por exemplo, Dickinson, então com 21 anos, provoca a amiga com uma historieta saborosamente sarcástica, que poderia passar à solta pelos olhos de um crítico, não fosse o significado literário que ali se esconde: escreve que, certa vez, enquanto o ministro condenava as impropriedades da Igreja Católica num de seus sermões, ela pensava em qual vestido deveria usar para dar boas-vindas a sua querida amiga Susan. Quando já decidia sobre a dúvida, o ministro dá um furioso golpe sobre a mesa, do qual ela até então ainda não se recuperara, não obstante a súbita decisão sobre o vestido lhe ter ocorrido (C96, p. 216). Essa oposição consciente entre a rebeldia amorosa e as admoestações da Igreja, ou antes, essa antítese entre liberdade sentimental e opressão religiosa, sempre lhe fora um caro motivo que promovesse a figura da rebelde obstinada. Dickinson teria usado o mesmo artifício com sua amiga Emily Fowler Ford, dois anos depois, em 1854, quando lhe confidenciou: "and it makes me so happy to think of writing you that I forget the sermon and minister and all, and think of none but you...” (C161, p. 293). E é espantoso que ela tenha criado imagem semelhante, décadas depois, numa carta a Otis Lord, magistrado de Massachusetts por quem ela se dizia apaixonada já na idade madura: "While others go to Church, I go to mine, for are not you my Church, and have we not a Hymn that no one knows but us?" (C79o, p. 753). Seria esse talvez, ou pelo menos próximo disso, o tema do famoso poema "Some keep the Sabbath going to church" (P236, I, p. 258): o céu calvinista prometido pelos ministros, confrontado com a vivência celestial do amor aqui na terra.

É especialmente nas cartas da primeira fase que Emily Dickinson

5 O amor de Emily Dickinson por Susan Gilbert foi explorado por biógrafos como Sewall (1997), Habegger (2001), Johnson (1965) e Kirk (2004), e por fim, no volume com coletânea de cartas da poeta à cunhada, organizada por Ellen Hart e Martha Nell Smith (1998). Richard Sewall aponta que as cartas de Emily Dickinson a Susan Gilbert são como cartas de amor, embora a poeta lhe atribua o papel de irmã, e mesmo a partir da poesia, é possível compreender que Emily deve ter se sentido frustrada com um amor não materializado, chegando a impor para si mesma uma conduta severamente puritana, quando deixou de visitar por pelo menos 15 anos a amiga e cunhada que morava na casa da frente (SEWALL, 1997, p. 163, 198-199 e 214). 
devota sentimentalidades e afetos amorosos a muitas de suas amigas de juventude: Abiah Root, Jane Humphrey, Emily Fowler Ford, Susan Gilbert - correspondências interrompidas, por vezes abruptamente, quando as jovens amigas se dedicavam à vida conjugal, com exceção da cunhada Susan, com quem Dickinson manteve uma espantosa e complexa interlocução por toda a vida. A linguagem erotizada, tomada de ardor, verdadeiro exercício retórico de poesia amorosa às amigas juvenis, não deixa de insinuar uma sexualidade ambígua da parte de Emily. Ellen Hart e Martha Nell Smith (1998, p. xiv), no entanto, pontuam que as jovens vitorianas do séc. XIX, talvez em razão das restrições sexuais, frequentemente se envolviam em relações românticas e afetivas entre si, não obstante a dimensão não-sexualizada desses idílios, o que por certo representaria muito mais uma paixão adolescente do que um amor maduro e erotizado: enfim, ardores homoeróticos de mocinhas consumidoras de literatura amorosa, caso não aplicável a Dickinson e Susan Gilbert, sustentadas num envolvimento mais profundo e duradouro.

As cartas de Emily a Susan - a querida Susie, ou Sue, a que ela se refere - são uma das mais elevadas referências do epistolário, no que tange a relações afetivas. Juntas, compuseram o volume Open me carefully: Emily Dickinson's intimate letters to Susan Huntington Dickinson, editado por Ellen Louise Hart e Martha Nell Smith (1998). No todo, a variedade temática e estilística dessas cartas, somada ao conjunto de informações autobiográficas, bem como aos próprios elementos de ficção literária em outros textos, torna a correspondência entre Dickinson e Susan um modelo poético do mais alto valor nas letras americanas.

Hart e Smith (1998, p. 148) apontam que, a julgar pela dimensão e conteúdo das cartas no período entre 1865-1875, época tardia na vida de Emily Dickinson, seu amor e desejo pela amiga e cunhada teriam permanecido. À Susie dos anos de ginásio, a poeta oferece a linguagem retórica e amorosa já antes dedicada a outras de suas amigas, mas o diálogo posterior (da época em que as duas, já unidas pela família, eram vizinhas de frente), se torna complexo, profundo, por vezes incompreensível. Em 1852, mocinhas ainda as duas amigas, Dickinson não escondia a volúpia de escrever a seu objeto de amor, gesto que se harmoniza com o poema 70o, sobre o êxtase de receber uma carta: "I have been hard at work this morning, and I ought to be working now but I cannot deny myself the luxury of a minute or two with you" ( $\mathrm{C}_{73}$, p. 175). A ansiedade da espera, o desejo do encontro, o conformismo no abandono (Susan teria se casado com Austin Dickinson em 1856, e o nascimento do primeiro filho, cinco anos depois, desencadeava em Emily um sentimento de perda), a renúncia ao amor, enfim, tudo isso 
compõe um acervo de elementos biograficamente ricos, porém a sugerir no epistolário uma verve algo romântica e ficcional. Também em 1852, em carta explicitamente amorosa, Dickinson queixava-se do silêncio que pairava entre as duas, sobre a união de duas almas: "You and I have been strangely silent upon this subject, Susie, we have often touched upon it, and as quickly fled away, as children shut their eyes when the Sun is too bright for them" (C93, p. 209-210). Num bilhete tardio a Susan, de 1885, um ano antes da morte, depois de uma longa existência de afeição profunda, depois das perdas que a vida impõe (do pai, da mãe, do filho de Susan, que morreu prematuramente aos 8 anos), Dickinson pontua a angústia do distanciamento, e a renúncia do amor acompanhada de uma ternura que ainda permanece, como a vida que submerge do abismo: "Emerging from an Abyss, and reentering it - that is Life, is it not, Dear? The tie between us is very fine, but a Hair never dissolves" (C1024, p. 893). A par da vida, e conferindo-lhe significados, a própria poesia.

Embora seja supérflua a busca de uma resposta a essa ambiguidade sexual de Emily Dickinson, não é sem interesse que se observa aquela antítese sempre recorrente entre a rebeldia anticlerical e os arroubos da paixão amorosa. É sintomático que os dois temas se encontrem e se entrecruzem com variações a assumir tão alto significado no epistolário da escritora. Quando se pensa que Dickinson buscava construir nas suas cartas uma espécie de sujeito identitário, a representar o esboço traçado de um indivíduo romântico, as relações conflituosas entre liberdade amorosa e opressão eclesiástica (assunto repisado no Romantismo), se tornam motivo de grande interesse. Emerson acorria-lhe nas horas de aflição, e sua "religião sem templos e sem deuses", anunciada nos ensaios, se desdobrava em multiplicidades temáticas nas cartas de Emily Dickinson, mas especialmente em sintonia com aquela religião sentimental do amor físico e espiritual.

Dickinson, contudo, teve olhos plenos de má vontade para outras faces contidas nos Ensaios de Emerson. Não abraçou a concepção mística da "supra-alma", por exemplo, e diferentemente de Walt Whitman, não foi capaz de se ver representada no ensaio "O poeta” (quando o ensaísta buscava em vão pelo poeta da eternidade na América), por se tratar ali de uma estética algo masculina e de certa forma nacionalista. A Emerson, apesar de moderno, antiescravagista e atento à situação social feminina, não teria ocorrido que o "poeta da América" poderia ser uma mulher, conforme consideram alguns críticos: 
turn out to be a woman. Emerson associated the poet, the "namer and sayer", both with Adam and with the Son of the Trinity, and the metaphor for the poetic process is both sexually and theologically male; the end of poetry is that "thought may be ejaculated as Logos, or Word" (Catherine Tufariello, "The remembering wine': Emerson's influence on Whitman and Dickinson", in PORTE \& MORRIS, 1999, p. 174-175).

Com relação ao patriarcalismo e à autoridade masculina, elementos típicos de sua cultura calvinista e que subliminarmente caracteriza o ensaio de Emerson, Dickinson parece ter tido dramas pessoais, o que, por certo, sintetiza dramas femininos da época vitoriana nos Estados Unidos. Pelo menos nas cartas, dirigiu-se a seus interlocutores masculinos de forma respeitosa (mesmo que eventualmente dispare ironias pungentes), como se lhes atribuísse certa autoridade social e patriarcal, enquanto com as amigas, solta-se numa linguagem confessional, íntima e curiosamente reveladora. Isso denuncia até que ponto ela mesma parece ter se sentido pouco à vontade diante do poder dominador das identidades masculinas, tendo na figura do homem (o pai, o pastor, o próprio Deus) uma espécie de princípio patriarcal de proteção e autoridade, mas não exatamente de amor. Essas particularidades históricas que se elevam à identidade de Emily Dickinson (calvinismo, misoginia, autoridade patriarcal, o Deus dominador) podem ser justificativa bem mais sólida para a natureza romântica e erótica das cartas às amigas do que a própria sexualidade em si.

As cartas possivelmente endereçadas a Benjamin Newton e Charles Wadsworth, homens com quem ela teria se "envolvido", talvez amorosamente, conforme críticos, não chegaram a nós, e portanto, não é possível emitir qualquer juízo sobre elas - se é que existiram em quantidade expressiva. A Charles Wadsworth podem ter sido escritas (porém não enviadas) as enigmáticas três cartas a um suposto "Mestre", não identificado. São curiosos documentos em que a escritora anseia por uma união espiritual com o mestre que lhe oferecera uma espécie de redenção ${ }^{6}$. Dickinson conhecera Wadsworth em 1855, numa de suas raríssimas viagens, à Filadélfia, e ficara encantada com os sermões daquele pastor presbiteriano de eloquência apaixonada. Conquanto não tenha havido o interesse amoroso propriamente (alguns biógrafos dizem

6 Habegger (2002, p. 417-418) enxerga em Charles Wadsworth o possível destinatário das "cartas ao mestre". Richard Sewall (1997, p. 519-520), observador perspicaz, prefere compreender as cartas como matéria literária, como produto da arte, que serviram de matriz ou corpo de ideias para muitos dos poemas da escritora. 
que sim), Wadsworth mudou a vida da jovem poeta, pois que daí em diante, ela consolidaria forte anseio pela amizade de homens mais velhos, especialmente clérigos, como referências espirituais. De qualquer modo, como define Sewall (1997, p. 453), a relação dos dois ainda é um mistério.

Quanto às cartas ao juiz Otis Phillips Lord, estas são surpreendentes na temática amorosa, sobretudo para o que significam naquela altura da vida de Emily Dickinson (os dois começaram a se corresponder em 1878, ela com quase 50 anos), mas mesmo sob esse ponto de vista, a correspondência adquire contorno notoriamente literário. Lord, magistrado famoso que servira à legislatura de Massachusetts e ao senado estadual, dezoito anos mais velho que Emily (na verdade, fora amigo de seu pai), tornara-se viúvo em 1877, e a proximidade com os Dickinson o teria arrastado a forte interesse amoroso pela poeta. Em 1878, pediu-a em casamento, o que ela, dada à vida de recolhimento e solidão, naturalmente não aceitou. Thomas Johnson, nos comentários à coletânea epistolar da escritora, considera: "The surviving letters and drafts of letters which ED wrote him about this time indicate that she was very much in love with the Judge. The attachment seems to have been mutual" (JOHNSON, 196o, p. 949). Sim, nas cartas de Emily, pelo menos, é possível entrever afeição e proximidade amorosa, eventualmente declarações de amor contidas, mas de natureza diferente do fervor erotizado das cartas às amigas, seja pela idade em que as emoções e os sentimentos esfriam, seja pela posição social do juiz:

My lovely Salem smiles at me. I seek his Face so often - but I have done with guises.

I confess that I love him - I rejoice that I love him - I thank the maker of Heaven and Earth - that gave him me to love - the exultation floods me. I cannot find my channel - the Creek turns Sea - at thought of thee - $\left(C_{559}\right.$, p. 614-615)

Amorosa, imaginativa, Dickinson parece se valer dos artifícios retóricos de sua própria poesia na correspondência com Otis Lord, e o acervo de sua linguagem acaba denunciando certo artificialismo em que os amantes são como que personagens num jogo romanesco. Não parece vida, mas literatura. Maduros, culturalmente oprimidos pela severidade puritana, ambos, Lord e Dickinson, devem ter sentido razões pessoais para cultivar a ficção amorosa: Dickinson enxergava no juiz o velho anseio de amizade masculina, figura emblematicamente espiritualizante, ao mesmo tempo em que buscava saídas para a existência tediosa, bem como respostas (literárias, diga-se) à sua "religião amorosa". Uma carta de Emily a Lord ( $C_{562}$, p. 617), em que a imagem farsesca de Cupido 
ensinando a Jeová a arte da feitiçaria revela gracejos sobre a moral religiosa, pode nos dar conta do quanto as relações entre opressão religiosa e liberdade sexual haveriam de representar para ambos. Outras cartas vão aos poucos insinuando o peso da consciência religiosa se impondo sobre a ficção erótica, e sugerindo linhas de força e polaridades de uma tensão emocional: "Perhaps, please, you are sinful? Though of Power to make Perdition divine, who can punish you?" ( $C_{561}$, p. 616$)$, ela pergunta ao "namorado". Nesse jogo de insinuações, em que a ficção se arroga privilégios frente à natureza civilizatória da moral religiosa, as cartas de Emily Dickinson a Otis Lord talvez sejam o mais clássico exemplo da construção de identidades postiças no epistolário da poeta americana. Um extraordinário modelo de inventividade e literariedade em epístolas, tendo o ensaio como base reflexiva.

A par desse quadro subjetivo na criação de uma autoimagem, não será inútil dizer que as cartas de Emily Dickinson, especialmente aquelas escritas numa fase madura, a partir de 1862, são essencialmente idiossincráticas e acompanham a tendência obscura e enigmática de alguns poemas. Ler a epístola equivale-se a ler a poesia - seja no estilo, no corpo de ideias, seja na originalidade da força poética, seja no abuso das rupturas sintáticas com a língua inglesa. Na correspondência de 25 anos, Thomas Higginson tentou em vão domesticar-lhe o estilo e a obstinação na quebra de regras, e a própria Dickinson o teria chamado de preceptor, assinando as cartas como "Your Scholar" (ironia, ou ato de humildade?); no entanto, por mais que o crítico lhe tenha feito "cirurgias" (expressão dela) em cada poema a ele enviado, a escritora jamais seguiu sequer uma única de suas recomendações. Já numa carta de agosto de 1862, ela recolhe aqui e ali alguma justificativa que dê conta do estilo enigmático, desajeitado, a literatura como que feita às canhas: "I had no Monarch in my life, and cannot rule myself, and when I try to organize - my little Force explodes - and leaves me bare and charred -"; e depois teria completado: "I shall observe your precept - though I dont understand it, always" (C271, p. 414).

Dickinson parece ter cultivado o gosto pela obscuridade e pela falta de regras - dois valores de estima à opinião romântica. "Pode-se dizer muitas coisas em favor das regras, mais ou menos o que se pode dizer em louvor da sociedade burguesa. [...] toda regra sufoca o verdadeiro sentimento e a verdadeira expressão da natureza", dirá o jovem Werther, numa de suas cartas a seu interlocutor Wilhelm (GOETHE, 1999, p. 19). Dickinson também deu vazão às coisas da natureza em detrimento das regras, e mostrou-se consciente disso, especialmente nas cartas. Admiradora de David Thoreau, o ensaísta da liberdade e da rebeldia que 
vinha incomodando autoridades americanas na época, a poeta de Amherst seguiu de perto a conduta estampada no Walden, em que se defende a bandeira do individualismo, a qual, sozinha, soergue igualmente outra bandeirada de consequências: a crítica do senso comum, o elogio da solidão e da loucura, a procura interior, o desejo de obscuridade: "É uma exigência ridícula da Inglaterra e dos Estados Unidos que você deva falar de uma maneira que possam entendê-lo. Não é assim que crescem os homens nem os cogumelos. Como se isso fosse importante, e não houvesse o suficiente para que o entendam" (THOREAU, 2010, p. 306). Thoreau, no seu grande ensaio Walden, ensinava a crítica da civilização burguesa, nos seus aspectos mais essenciais, e por extensão, a recusa da sabedoria social, do trabalho, do senso comum, naquilo que ele tem de restritivo à exclusividade subjetiva. Dickinson, que teve notória consciência da incomunicabilidade de sua poesia, buscou integrar-se ao mundo por meio das cartas, mesmo que também ali, frente às lições aprendidas com a leitura de Thoreau, não tenha conseguido fugir à tentação da obscuridade, e ao próprio elogio da solidão e da loucura.

Mas venhamos a uma síntese: o epistolário de Emily Dickinson é um campo vasto de gêneros e estilos, que vai da simples correspondência familiar às cartas mais obscuras e filosóficas, passando por enigmáticos bilhetes que expressam máximas, sentenças, charadas, comentários literários, epígrafes, frases soltas, poemas, fragmentos, composições, e tanto mais se torna profundo e investigador, quanto mais se avança em sua leitura. Inúmeras cartas obedecem à própria estrutura da poesia, com versos, imagens, metáforas, e por fim, com a grandeza e as particularidades de um sujeito inteiramente devotado, por toda uma vida, ao ofício da poesia. Dá para entender por que razão ela confidenciava a Higginson que a correspondência com ele salvara-lhe a vida.

Nos primeiros anos de interlocução com amigos e familiares (até mais ou menos 1852), quando a menina de Amherst ainda não descobrira a dimensão da futura atividade poética, as cartas iniciais revelam a jovem romântica, afetuosa, porém transgressora e anticlerical, a insinuar paixões e amores às amigas, exercício retórico e poético que se desdobraria em reflexões mais maduras à cunhada Susan Gilbert, a quem ela enviou pelo menos 150 cartas e centenas de poemas. Nas primeiras cartas aos homens (com exceção do irmão Austin), eventualmente a amigos intelectualizados, o tom comedido começa aos poucos, a partir de 1860, a dar espaço a sentimentos de afeto e gratidão: nas cartas a Samuel Bowles, importante jornalista da época, por exemplo, com quem Dickinson cultivou amizade e farta correspondência, o estilo conquista maturidade 
e as afeições se alternam entre manifestações de apreço e vagas investidas amorosas, mas sempre no campo dos sentimentos familiares (Bowles era amigo da família). Com as mulheres, a Sra. Holland, por exemplo (esposa do Dr. Josiah Gilbert Holland), igualmente amiga da família, mas a quem Emily chamava de irmã, os assuntos são diversos, e podem variar de uma simples receita culinária a uma reflexão sobre a morte e a condição humana. Com as primas Louise e Frances Norcross, mais jovens que Emily e a quem ela devota os mais sinceros sentimentos de afeição, as questões igualmente se alternam, mas a elas a poeta prefere as matérias amenas sobre flores e pássaros, típicas conversações femininas da época vitoriana. Helen Hunt Jackson, romancista prestigiada em seu tempo, hoje uma referência bem menos significativa nas letras de língua inglesa, também é nome emblemático que ocorre nas cartas de Emily Dickinson, apesar de tão poucos documentos terem sobrevivido: Helen foi a única celebridade do séc. XIX a considerar a sério a poesia de Emily, sua colega de ginásio. Susan Gilbert continua sendo de longe o nome mais significativo dentre os interlocutores de Emily Dickinson, aquela identidade que sintetiza os diversos anseios da poeta, nas fronteiras entre o amor e as reflexões sobre a poesia.

No âmbito de sua própria vida, Dickinson buscou a solidão e o recolhimento, no espaço de um quarto, na casa de seu pai. Nas cartas, procurou o exercício da interlocução como atividade literária. Seu epistolário revela a escritora na prática de sua função poética, a compor elementos de ficção que dialoguem com os fatos quotidianos da vida, ampliando significados e traçando um perfil autobiográfico, em que vida e expressão literária coexistem e se misturam, sem que se possa traçar fronteiras e limites entre eles. A partir de um momento em sua vida, as cartas tornaram-se o único veículo de comunicação com o mundo, levando e trazendo notícias, ou mesmo desempenhando a função poética, naquela prática rotineira de construção de uma identidade autobiográfica, em que projeções de ficção e elementos da realidade se completam. Envolvida pelos ensaios de Emerson e Thoreau, e rodeada pela literatura vitoriana de seus contemporâneos (Elizabeth Browning, Henry Wadsworth Longfellow), Dickinson utilizou-se de seu próprio epistolário para compor também ela uma trama de novos sentidos, a fazer valer uma literatura outra, enriquecida por elementos da autobiografia, mas acima de tudo, senhora de uma realidade diversa, em que personagens de uma ficção se envolvem nas amarras de uma identidade plenamente imaginada. Dickinson, não vivendo na vida os diversos mundos sonhados, viveu no epistolário o sabor de outras 
identidades postiças.

\section{REFERÊNCIAS BIBLIOGRÁFICAS}

EBERWEIN, J. D. \& MACKENZIE, C. Reading Emily Dickinson's letters: critical essays. Amherst/ Boston: University of Massachusetts Press, 2009.

EMERSON, Ralph Waldo. Ensaios. Trad. Carlos Graieb e José M. Mariani de Macedo. Rio de Janeiro: Imago, 1996.

. Ensaios. Trad. José Paulo Paes. São Paulo: Cultrix, 1966.

FRANKLIN, R.W. (ed.). The Poems of Emily Dickinson (variorum edition). Cambridge, MA: The Belknap Press/ London: Harvard University Press, 1998.

GOETHE, J. Wolfgang. Os sofrimentos do jovem Werther. Trad. Leonardo César Lack. São Paulo: Nova Alexandria, 1999.

JOHNSON, Thomas. Mistério e solidão: a vida e a obra de Emily Dickinson. Trad. Vera das Neves Pedroso. Rio de Janeiro: Lidador, 1965.

JOHNSON, Thomas (ed.). The letters of Emily Dickinson. Cambridge, MA./ London: The Belknap Press of Harvard University Press, 1960.

HABEGGER, Alfred. My wars are laid away in books: The life of Emily Dickinson. New York: The Modern Library, 2001.

HART, Ellen L. \& SMITH, Martha Nell. Open me carefully: Emily Dickinson's intimate letters to Susan Huntington Dickinson. Ashfield, MA: Paris Press, 1998.

KIRK, Connie Ann. Emily Dickinson: A Biography. West Port, Connecticut: Greenwood Press, 2004.

MARTIN, Wendy. "Emily Dickinson”, in: ELLIOTT, Emory (ed.). Columbia Literary History of the United States. New York: Columbia University Press, 1988.

PORTE, Joel \& MORRIS, Sandra. The Cambridge Companion to Ralph Waldo Emerson. Cambridge: Cambridge University Press, 1999.

SEWAL, Richard. The life of Emily Dickinson. Cambridge, MA: Harvard University Press, 1997.

SMITH, Martha Nell \& LOEFFELHOLZ, Mary (ed.). A companion to Emily Dickinson. Malden: Blackwell Publishing, 2008.

St. ARMAND, Barton Levi. Emily Dickinson and Her Culture: The Soul's Societ. Cambridge: Cambridge University Press, 2009.

THOREAU, Henry David. Walden. Trad. Denise Bottmann. Porto Alegre: L\&PM, 2010. 
WOLFF, Cynthia G. "Emily Dickinson", in: PARINI, Jay (ed.). The Columbia History of American Poetry. New York: Columbia University Press, 1993. 
